\title{
Model Optimasi Jaringan Rantai Pasok Pada Sistem Informasi Harga Karet Rakyat Berbasis Web
}

\author{
Muhammad Irvai*, Muhammad Izman Herdiansyah \\ Fakultas Komputer, Magister Teknik Informatika, Universitas Bina Darma, Palembang, Indonesia \\ Email: 1,"irvaimuhammad9@gmail.com, ${ }^{2}$ m.herdiansyah@binadarma.ac.id \\ Email Penulis Korespondensi: irvaimuhammad9@gmail.com
}

\begin{abstract}
Abstrak-Permasalahan rantai pasokan secara tradisional menimbulkan pendistribusian hasil produksi karet rakyat tidak efisien. Ruang lingkup penelitian berada di kabupaten Musi Rawas. Tujuan penelitian ini adalah mengoptimalkan rantai pasok karet rakyat dari setiap saluran rantai pasok menggunakan sistem informasi. Metode analisis yang digunakan dalam penelitian ini adalah metode Linier Programming (LP). Kapasitas alat angkut dan jam tenaga kerja dijadikan sebagai fungsi kendala sedangkan fungsi tujuannya adalah memaksimalkan keuntungan distribusi dari setiap saluran rantai pasok karet. Dari hasil pengujian aplikasi Quantitative Management (QM) dengan sampel petani 1, pengumpul desa 1 dan pengumpul kecamatan 1 pada saluran pertama didapatkan solution produk jenis A yakni sebesar 625 dan keuntungan X1=8218, kemudian dikalikan jadi keuntungannya sebesar Rp. 5.136.250. Dari hasil pengujian aplikasi Quantitative Management (QM) dengan sampel petani dan pengumpul desa/kecamatan 1 pada saluran kedua didapatan solution produk jenis A yakni sebesar 500 dan keuntungan X1=7923, keuntungannya sebesar Rp. 3.961.500. Dari hasil pengujian aplikasi Quantitative Management (QM) dengan sampel petani dan UPPB 1 pada saluran ketiga didapatkan solution produk jenis B yakni sebesar 562.5 dan keuntungan X2=9897, keuntungannya sebesar Rp. 5.567.063. Jadi dari hasil analisis menggunakan aplikasi QM, keuntungan maksimal dari rantai pasok karet rakyat kabupaten Musi Rawas terdapat pada saluran ketiga.
\end{abstract}

Kata Kunci: Optimasi; Rantai Pasok; Linier Programming; Karet; Web

Abstract-The supply chain problems have traditionally resulted in inefficient distribution of the people's rubber production. The research scope is in Musi Rawas district. The purpose of this research is to optimize the people's rubber supply chain from each supply chain channel using an information system. The method of analysis used in this research is Linear Programming (LP). Conveyance capacity and labor hours serve as constraint functions, while the objective function is to maximize distribution profits from each rubber supply chain channel. From the results of testing the Quantitative Management (QM) application with a sample of farmers 1, village collectors 1 and sub-district 1 collectors in the first channel, a solution of type A products is obtained, which is 625 and a profit of $\mathrm{X} 1=8218$, then multiplied into a profit of Rp. 5,136,250. From the results of testing the Quantitative Management (QM) application with a sample of farmers and village / sub-district collectors 1 in the second channel, it was found that the product type A solution was 500 and the profit X1 = 7923, the profit was Rp. 3,961,500. From the results of testing the Quantitative Management (QM) application with a sample of farmers and UPPB 1 in the third channel, the solution for type B products is 562.5 and the profit X2 $=9897$, the profit is Rp. 5,567,063. So from the results of the analysis using the QM application, the maximum benefit from the people's rubber supply chain in Musi Rawas district is in the third channel.

Keywords: Optimization; Supply Chain; Linier Programming; Rubber; Web

\section{PENDAHULUAN}

Areal perkebunan karet yang terdapat di Sumatera Selatan hampir tersebar di setiap kabupaten dan kota. Lahan atau area perkebunan karet di Sumatera Selatan terluas berada di kabupaten Musi Rawas, dengan luas area perkebunan mencapai 333,282 hektar dengan hasil karet 264,178 ton. Daerah terluas kedua berada di kabupaten Muara Enim dengan luas area perkebunan mencapai 220,256 hektar dan hasil karet karet sebesar 242,446 ton. [1] Hasil produksi karet di kabupaten Musirawas berasal dari tanaman karet rakyat. Jumlah dan kualitas karet karet yang tinggi perlu diprioritaskan tetapi dalam waktu pendistribusian karet rakyat juga harus diperhatikan untuk memenuhi permintaan pabrik karet terhadap karet karet sesuai dengan kebutuhan pabrik pengolahan karet.

Rantai pasok merupakan sistem dimana suatu organisasi dapat menyalurkan barang karet dan jasanya ke para pelanggan. Rantai pasok ini juga merupakan jejaring dari berbagai organisasi yang saling keterkaitan atau berhubungan yang memiliki tujuan yakni menyelenggarakan pengadaan atau penyaluran barang secara baik. [2] Adapun masalah yang menjadi faktor gagalnya adalah penyimpanan hasil karet karet yang terlalu lama dan waktu pendistribusian yang lama menimbulkan optimasi pendistribusian karet tidak efisien.

Tujuan suatu sistem dari manajemen rantai pasok yakni untuk melakukan suatu koordinasi sebuah kegiatan dalam rantai pasok tersebut sehingga dapat dimaksimalkan sebagai keunggulan kompetitif dan dapat bermanfaat bagi konsumen akhir dari proses rantai pasok tersebut. [3]

Pada pengelolaan sistem rantai pasok (supply chain) karet rakyat, terdapat 2 faktor yang mempengaruhi sistem tersebut yakni tingkat efisiensi dalam sistem pemasaran karet rakyat dan kapasitas penampungan pabrik pengolahan karet.. Rantai pasok karet alam rakyat di Kabupaten Musirawas umumnya terdapat tiga pola saluran pemasaran karet. Pola pertama terdiri atas 4 anggota rantai pasok, meliputi petani, pedagang pengumpul desa, pedagang pengumpul kecamatan dan pabrik pengolahan karet (crum rubber). Pola kedua terdiri dari 3 anggota rantai pasok, meliputi petani, pedagang pengumpul desa/kecamatan dan pabarik. Pola ketiga terdiri atas 3 anggota rantai pasok, meliputi petani/kelompok tani, Unit Pengolahan dan Pemasaran Bokar (UPPB) dan pabrik pengolahan karet. 
Pada penelitian-penelitian sebelumnya, membahas mengenai model optimasi perancangan jaringan rantai pasok biomassa dari tanaman kelapa sawit. Pada penelitian ini, tahapan penelitian ini diawali dengan studi pendahuluan untuk mengetahui potensi biomassa. Selanjutnya dilakukan perancangan model optimasi chain supply chain dengan mengidentifikasi aktivitas rantai pasokan, mengetahui karakteristik sistem rantai pasokan dan membuat rumusan model matematika. [4] Selain itu, penelitian lainnya membahas mengenai model manajemen rantai pasok benih unggul karet, khususnya elemen atau pelaku utama yang terlibat serta optimalisasi rantai pasok agar penyediaan dan distribusi benih unggul karet berjalan baik dan mudah diadopsi oleh petani. Hasil analisis diharapkan dapat mendukung kebijakan dan program pengembangan karet secara nasional [5]. Selanjutnya terdapat pula hasil penelitian mengetahui jumlah produksi optimal dan keuntungan maksimal di perabot mebel. Metode analisis data yang digunakan adalah pemrograman linier dengan perhitungan menggunakan QM POM.[6]

Tujuan penelitian ini adalah untuk memaksimalkan keuntungan biaya distribusi rantai pasok karet di kabupaten Musi Rawas dengan metode pemrograman linier. Metode analisis data dengan pemrograman linier menggunakan software QM POM sebagai pengujian data. Data karet juga disajikan melalui halaman website berdasarkan saluran yang ada di kabupaten Musi Rawas. Kontribusi utama dari penelitian ini adalah mengkaji penerapan model jaringan rantai pasok karet untuk mengoptimalkan dan menyelesaikan masalah-masalah pada rantai pasok karet di kabupaten Musirawas.

\section{METODOLOGI PENELITIAN}

\subsection{Tahap Penelitian}

Penelitian ini dilakukan dengan beberapa tahapan, sebagai berikut:

a. Pengumpulan Data

b. Penentuan biaya beban dan keuntungan penjualan

c. Penentuan fungsi tujuan

d. Penentuan batasan

e. Penentuan variabel keputusan

f. Pengolahan data dengan software linier programming dan website

\subsection{Biaya Beban}

Distribusi karet untuk setiap saluran rantai pasok tentunya memiliki biaya-biaya terkait distribusi karet yakni biaya beban. Biaya beban distribusi pada saluran pertama, kedua dan ketiga berupa upah karyawan, bahan bakar minyak dan servis kendaraan. Biaya beban saluran I, Saluran II dan Saluran III dihitung menggunakan rumus:

$$
\sum B d_{c a l}=\sum \boldsymbol{G}_{d}+\sum \boldsymbol{B}_{d}+\sum \boldsymbol{S}_{d}
$$

Dimana:

$\sum \boldsymbol{B d}_{\boldsymbol{c a l}}=$ Total biaya beban

$\sum \boldsymbol{G}_{\boldsymbol{d}}=$ Biaya gaji karyawan

$\sum \boldsymbol{B}_{\boldsymbol{d}}=$ Biaya BBM kendaraan

$\sum \boldsymbol{S}_{\boldsymbol{d}}=$ Biaya servis kendaraan

\subsection{Formulasi Keuntungan Penjualan}

Untuk mendapatkan data keuntungan penjualan setiap saluran rantai pasok dapat digunakan formulasi berikut:

a. Saluran Pertama

Berikut formulasi untuk menentukan keuntungan pada saluran pertama:

$$
\begin{gathered}
\left.\left.F_{a}, F_{b}=\left(\left(\sum_{p=1}^{N} \sum_{k=1}^{S} U a g_{c p k} x \sum_{t=1}^{T} \sum_{k=1}^{S} X_{p c k l}\right) / \sum_{k=1}^{S} T o t X_{p c k l}\right)\right)+\left(\left(\left(\sum_{c=1}^{D} \sum_{k=1}^{S} U b_{\text {gack }} x \sum_{l=1}^{Q} \sum_{t=1}^{T} \sum_{k=1}^{S} X_{\text {cakl }}\right)-B d_{c a l}\right) / \sum_{k=1}^{S} \operatorname{Tot} X_{\text {cakl }}\right)\right) \\
\left.+\left(\left(\left(\sum_{a=1}^{W} \sum_{k=1}^{S} U c_{g f a k} x \sum_{l=1}^{Q} \sum_{t=1}^{T} \sum_{k=1}^{S} X_{a f k l}\right)-B u_{a f l}\right) / \sum_{k=1}^{S} T o t X_{a f k l}\right)\right) \ldots \ldots \ldots \text { (2) }
\end{gathered}
$$

Indeks:

$F_{a}=$ Keuntungan karet karet A (saluran I)

$F_{b}=$ Keuntungan karet karet B (saluran I)

Parameter:

$X_{p c k l}=$ Kuantitas karet dari petani A ke pengumpul desa

Tot $X_{p c k l}=$ Total Kuantitas karet dari petani ke pengumpul desa

$X_{\text {cakl }}=$ Kuantitas karet dari pengumpul desa ke pengumpul kecamatan

Tot $X_{\text {cakl }}=$ Total Kuantitas karet dari pengumpul desa ke pengumpul kecamatan

$X_{a f k l}=$ Kuantitas karet dari pengumpul kecamatan ke pabrik

Tot $X_{a f k l}=$ Total Kuantitas karet dari pengumpul kecamatan ke pabrik

$U a_{g c p k}=$ Harga karet dari pengumpul desa ke petani $\mathrm{A}$ 


\section{JURNAL MEDIA INFORMATIKA BUDIDARMA}

Volume 5, Nomor 2, April 2021, Page 600-608

ISSN 2614-5278 (media cetak), ISSN 2548-8368 (media online)

Available Online at https://ejurnal.stmik-budidarma.ac.id/index.php/mib DOI 10.30865/mib.v5i2.2928

$U b_{\text {gack }}=$ Margin harga karet dari pengumpul kecamatan ke pengumpul desa

$U c_{g f a k}=$ Margin harga $g$ karet dari pabrik ke pengumpul kecamatan

$B d_{c a l}=$ Total biaya beban pengumpul desa

$B k_{a f l}=$ Total biaya beban pengumpul kecamatan

\section{b. Saluran Kedua}

Berikut formulasi untuk menentukan keuntungan pada saluran kedua:

$$
\begin{gathered}
G_{a}, G_{b}=\left(\left(\left(\sum_{o=1}^{N} \sum_{k=1}^{S} U o_{g r o k} x \sum_{t=1}^{T} \sum_{k=1}^{S} X_{o c k l}\right) / \sum_{k=1}^{S} \operatorname{Tot} X_{\text {ockl }}\right)\right)+\left(\left(\left(\sum_{a=1}^{W} \sum_{k=1}^{S} U r_{g f r k} x \sum_{l=1}^{Q} \sum_{t=1}^{T} \sum_{k=1}^{S} X_{r f k l}\right)\right.\right. \\
\left.\left.\left.-B g_{g f l}\right) / \sum_{k=1}^{S} \operatorname{Tot} X_{r f k l}\right)\right) \quad \ldots \ldots \ldots \ldots \ldots \ldots \ldots \ldots \ldots
\end{gathered}
$$

Indeks:

$G_{a}=$ Keuntungan karet karet A (saluran II)

$G_{b}=$ Keuntungan karet karet B (saluran II)

Parameter:

$X_{o c k l}=$ Kuantitas karet dari petani B ke pengumpul desa/kecamatan

Tot $X_{o c k l}=$ Total Kuantitas karet dari petani B ke pengumpul desa/kecamatan

$X_{r f k l}=$ Kuantitas karet dari pengumpul desa/kecamatan ke pabrik

Tot $X_{r f k l}=$ Total Kuantitas karet dari pengumpul desa/kecamatan ke pabrik

$U o_{\text {grok }}=$ Harga karet dari pengumpul desa/kecamatan ke petani B

$U r_{g f r k}=$ Margin Harga karet dari pabrik ke pengumpul desa/kecamatan

$B g_{g f l}=$ Total biaya beban pengumpul desa/kecamatan

c. Saluran Ketiga

Berikut formulasi untuk menentukan keuntungan pada saluran ketiga

$$
\begin{gathered}
P_{a}, P_{b}=\left(\left(\sum_{i=1}^{N} \sum_{k=1}^{S} U d_{g b i k} \times \sum_{t=1}^{T} \sum_{k=1}^{S} X_{i c k l}\right) / \sum_{k=1}^{S} \operatorname{Tot} X_{i c k l}\right)+ \\
\left.\left.\left(\left(\sum_{l=1}^{Q} \sum_{b=1}^{H} \sum_{k=1}^{S} U e_{g f b k} \times \sum_{k=1}^{S} X_{b f k l}\right)-B u_{b f l}\right) / \sum_{k=1}^{S} \operatorname{Tot} X_{b f k l}\right)\right) \ldots
\end{gathered}
$$

Indeks:

$P_{a}=$ Keuntungan karet karet A (saluran III)

$P_{b}=$ Keuntungan karet karet B (saluran III)

Parameter:

$X_{i c k l}=$ Kuantitas karet dari petani C ke UPBB

Tot $X_{i c k l}=$ Total Kuantitas karet dari petani ke UPBB

$X_{b f k l}=$ Kuantitas karet dari UPPB ke pabrik

Tot $X_{b f k l}=$ Total Kuantitas karet dari UPPB ke pabrik

$U d_{g b i k}=$ Harga karet dari UPPB ke petani $\mathrm{C}$

$U e_{g f b k}=$ Harga karet dari pabrik ke UPPB

$B u_{b f l}=$ Total biaya beban UPPB

\subsection{Formulasi Linier Programming}

Formulasi linier programming terdiri atas fungsi tujuan, variabel keputusan dan fungsi kendala. Fungsi tujuan dari model adalah memaksimalkan biaya keuntungan dari penjualan karet karet dari setiap saluran rantai pasok. Berikut ini formulasi fungsi tujuan dari setiap saluran:

a. Saluran pertama

$\mathrm{ZF}_{\text {Max }}=\mathbf{F}_{\mathbf{a}} \mathbf{X}_{1}+\mathbf{F}_{\mathbf{b}} \mathbf{X}_{2}$

Dimana:

$Z F_{\text {Max }}=$ Maksimal Keuntungan distribusi karet saluran pertama

$F_{a}=$ Keuntungan jenis karet A saluran pertama $(\mathrm{Rp} / \mathrm{kg})$

$F_{b}=$ Keuntungan jenis karet B saluran pertama $(\mathrm{Rp} / \mathrm{kg})$

$X_{1}=$ jenis karet A saluran pertama $(\mathrm{kg})$

$X_{2}=$ jenis karet B saluran pertama $(\mathrm{kg})$

b. Saluran kedua

$\mathbf{Z G}_{\mathbf{M a x}}=\mathbf{G}_{\mathbf{a}} \mathbf{X}_{\mathbf{3}}+\mathbf{G}_{\mathbf{b}} \mathbf{X}_{\mathbf{4}}$

Dimana:

$Z G_{\text {Max }}=$ Maksimal Keuntungan distribusi karet saluran kedua

$G_{a}=$ Keuntungan jenis karet A saluran kedua $(\mathrm{Rp} / \mathrm{kg})$

$G_{b}=$ Keuntungan jenis karet B saluran kedua $(\mathrm{Rp} / \mathrm{kg})$

$X_{3}=$ jenis karet A saluran kedua $(\mathrm{kg})$

$X_{4}=$ jenis karet B saluran kedua $(\mathrm{kg})$ 


\section{JURNAL MEDIA INFORMATIKA BUDIDARMA}

Volume 5, Nomor 2, April 2021, Page 600-608

ISSN 2614-5278 (media cetak), ISSN 2548-8368 (media online)

Available Online at https://ejurnal.stmik-budidarma.ac.id/index.php/mib

DOI 10.30865/mib.v5i2.2928

\section{c. Saluran ketiga}

$\mathbf{Z P}_{\text {Max }}=\mathbf{P}_{\mathbf{a}} \mathbf{X}_{5}+\mathbf{P}_{\mathbf{b}} \mathbf{X}_{6}$

Dimana:

$Z P_{\text {Max }}=$ Maksimal Keuntungan distribusi karet saluran ketiga

$P_{a}=$ Keuntungan jenis karet A saluran ketiga $(\mathrm{Rp} / \mathrm{kg})$

$P_{b}=$ Keuntungan jenis karet B saluran ketiga $(\mathrm{Rp} / \mathrm{kg})$

$X_{5}=$ Jenis Karet A saluran ketiga $(\mathrm{kg})$

$X_{6}=$ Jenis Karet B saluran ketiga $(\mathrm{kg})$

Variabel keputusan dalam penelitian yakni keuntungan dari total penjualan karet jenis A dan jenis B. Sedangkan fungsi kendala disini digunakan untuk mendefinisikan faktor kendala/pembatas dari penelitian. fungsi kendala pada penelitian terdiri atas kendala kapasitas alat angkut dan kendala jam tenaga kerja. Berikut formulasi untuk menentukan fungsi kendala yakni:

a. Kendala kapasitas alat angkut

Untuk mendapatkan hasil kendala kapasitas alat angkut untuk setiap saluran rantai pasok dapat dilihat dalam formulasi berikut:

Dimana:

$$
K f_{a} X_{1}+K f_{b} X_{2} \leq V a_{c l}
$$

$K f_{a}=$ Kuantitas karet A $(\mathrm{kg})$

$K f_{b}=$ Kuantitas karet B $(\mathrm{kg})$

$X_{1}=$ jenis karet $\mathrm{A}(\mathrm{kg})$

$X_{2}=$ jenis karet B $(\mathrm{kg})$

$V a_{c l}=$ Kapasitas maksimum moda transportasi $l$ dari pengumpul karet $(\mathrm{kg})$

b. Kendala jam kerja tenaga kerja

Untuk mendapatkan hasil kendala jam kerja tenaga kerja untuk setiap saluran rantai pasok dapat dilihat dalam formulasi berikut:

$$
T F_{a} X_{1}+T F_{b} X_{2} \leq+T a_{c l}
$$

Dimana:

$T F_{a}=$ Waktu angkut karet A (detik)

$T F_{b}=$ Waktu angkut karet B (detik)

$X_{1}=$ jenis karet $\mathrm{A}(\mathrm{kg})$

$X_{2}=$ jenis karet B $(\mathrm{kg})$

$T a_{c l}=$ Total waktu angkut karet dari pengumpul karet $c$ (detik)

\section{HASIL DAN PEMBAHASAN}

\subsection{Data Penelitian}

Data penelitian yang didapatkan dari hasil observasi dan wawancara secara langsung dengan pihak terkait yakni petani, pengumpul karet, UPPB dan dinas perkebunan kabupaten Musi Rawas pada bulan Januari 2020. Periode distribusi atau pengiriman produk karet alam rakyat di kabupaten Musi Rawas dilakukan dua kali untuk karet jenis produk A dan empat kali untuk karet jenis produk B.

Data penjualan untuk saluran pertama diambil pada bulan januari 2020 dengan dengan sampel data sebanyak 100 responden. Sebagai contoh untuk 1 petani, 1 pengumpul desa dan 1 pengumpul kecamatan. Ratarata kuantitas hasil produksi karet ditingkat petani 1 adalah 500 kilogram. Total kuantitas distribusi produksi karet ditingkat pengumpul desa 1 adalah 3500 kilogram. Total kuantitas distribusi produksi karet ditingkat pengumpul kecamatan 1 adalah 17500 kilogram.

Data penjualan untuk saluran kedua dengan sampel data sebanyak 80 responden. Sebagai contoh untuk 1 petani dan 1 pengumpul desa/kecamatan. Total kuantitas hasil produksi karet ditingkat petani 1 adalah 500 kilogram. Total kuantitas distribusi produksi karet ditingkat pengumpul desa/kecamatan 1 adalah 10000 kilogram.

Data penjualan untuk saluran ketiga dengan sampel data sebanyak 60 responden. Sebagai contoh untuk 1 petani dan 1 UPPB. Total kuantitas hasil produksi karet ditingkat petani 1 yakni 600 kilogram. Total kuantitas distribusi produksi karet ditingkat UPPB 1 adalah 9000 kilogram.

Hasil keuntungan penjualan pada saluran pertama, petani 1 dengan jenis produk A per kilogram sebesar Rp. 5.652, dan jenis produk B per kilogram sebesar Rp. 4.576. Keuntungan ditingkat pengumpul desa 1 dengan jenis produk A per kilogram sebesar Rp. 1.154, dan jenis produk B per kilogram sebesar per kilogram Rp. 1.049. Sedangkan keuntungan ditingkat pengumpul kecamatan 1 dengan jenis produk A per kilogram sebesar Rp. 1.412, dan jenis produk B per kilogram sebesar Rp. 1.110. Selanjutnya didapat keuntungan untuk saluran pertama ditambahkan antara petani, pengumpul desa dan kecamatan, maka keuntungan per kilogram jenis produk A sebesar Rp. 8.218 dan keuntungan per kilogram jenis produk A sebesar Rp. 6.736. 
Hasil keuntungan penjualan pada saluran kedua, petani 1 dengan jenis produk A per kilogram sebesar Rp. 6.452 dan jenis produk B per kilogram sebesar Rp. 5.373. Sedangkan keuntungan ditingkat pengumpul desa/kecamatan 1 dengan jenis per kilogram produk A sebesar Rp. 1.471 dan jenis produk B per kilogram sebesar Rp. 1.367. Keuntungan pada saluran kedua per kilogram jenis produk A sebesar Rp. 7.923 dan keuntungan per kilogram jenis produk B sebesar Rp. 6.740.

Hasil keuntungan penjualan pada saluran ketiga, petani 1 dengan jenis produk A per kilogram sebesar Rp. 9.700 dan jenis produk B per kilogram sebesar Rp. 8.752. Keuntungan ditingkat UPPB 1 dengan jenis produk A per kilogram sebesar Rp. 1.615 dan jenis produk B sebesar Rp. 1.146. Keuntungan saluran ketiga per kilogram jenis produk A sebesar Rp. 11.315 dan keuntungan per kilogram jenis produk A sebesar Rp. 9.897.

Selanjutnya untuk fungsi kendala terdapat dua fungsi yakni kendala kapasitas alat angkut dan kendala jam kerja tenaga kerja. Untuk saluran pertama, kapasitas alat angkut sebesar $17.500 \mathrm{~kg}$. Sedangkan untuk kendala jam tenaga kerja berkisar 4 jam tenaga kerja dengan 6 orang tenaga kerja dan dikalkulasikan per detik ( 6 orang*4 jam*3600 detik) berkisar 86.400 detik. Untuk saluran kedua, kapasitas alat angkut sebesar $10.000 \mathrm{~kg}$. Sedangkan untuk kendala jam tenaga kerja berkisar 4 jam tenaga kerja dengan 4 orang tenaga kerja dan dikalkulasikan per detik (4 orang*4 jam*3600 detik) berkisar 57.600 detik. Untuk saluran ketiga, kapasitas alat angkut sebesar 9.000 $\mathrm{kg}$. Sedangkan untuk kendala jam tenaga kerja berkisar 4 jam tenaga kerja dengan 2 orang tenaga kerja dan dikalkulasikan per detik ( 2 orang*4 jam*3600 detik) berkisar 28.800 detik.

\subsection{Pengujian Data}

\section{a. Saluran Pertama}

Hasil pengujian menggunakan aplikasi QM untuk mengoptimalkan keuntungan pada saluran pertama berdasarkan kendala-kendala pada saluran pertama dilihat pada gambar 1:

\begin{tabular}{|c|c|c|c|c|c|}
\hline \multicolumn{6}{|c|}{ Win Linear Programming Results } \\
\hline & $\mathrm{X} 1$ & $\mathrm{X} 2$ & & RHS & Dual \\
\hline Maximize & 8218 & 6736 & & & \\
\hline Kendala Kapasitas Alat Angkut & 28 & 25 & $<=$ & 17500 & 293,5 \\
\hline Kendala Jam Tenaga Kerja & 115 & 110 & $<=$ & 86400 & 0 \\
\hline Solution-> & 625 & 0 & & 5136250 & \\
\hline
\end{tabular}

Gambar 1. Hasil pengujian aplikasi QM pada saluran I

Dari hasil pengujian aplikasi QM didapatkan solution pada saluran pertama produk jenis A yakni solution sebesar 625. Jadi didapatkan perhitungan solution X1=625 dikalikan dengan keuntungan X1=8218. Jadi keuntungan maksimal saluran pertama petani 1, pengumpul desa 1 dan pengumpul kecamatan 1 bulan januari adalah Rp. 5.136.250.

Analisis sensitivitas pada petani 1, pengumpul desa 1 dan pengumpul kecamatan 1 pada saluran pertama dapat dilihat pada gambar 2 berikut:

\begin{tabular}{|l|r|r|r|r|r|}
\hline Variable & Value & Reduced Cost & Original Val & Lower Bound & Upper Bound \\
\hline X1 & 625 & 0 & 8218 & 7544,32 & Infinity \\
\hline X2 & 0 & 601,5 & 6736 & - Infinity & 7337,5 \\
\hline Constraint & Dual Value & Slack/Surplus & Original Val & Lower Bound & Upper Bound \\
\hline Kendala Kapasitas Alat Angkut & 293,5 & 0 & 17500 & 0 & 21036,52 \\
\hline Kendala Jam Tenaga Kerja & 0 & 14525 & 86400 & 71875 & Infinity \\
\hline
\end{tabular}

Gambar 2. Analisis Sensitivitas pada saluran pertama

Berdasarkan hasil analisis sensitivitas pada gambar 3, terdapat lower bound dan upper bound yang berguna untuk analisis sensitivitas pada saluran pertama:

1. Kendala kapasitas alat angkut

Upper bound: untuk proses pengangkutan karet, kapasitas alat angkut ditambahkan sampai berkisar $21.036 \mathrm{~kg}$ tidak akan mengubah solution diatas. Jika kapasitas alat angkut ditingkatkan maka akan mempengaruhi total biaya beban dan total keuntungan yang diperoleh.

Lower bound: untuk proses pengangkutan karet, batas bawah kapasitas pengangkutan bernilai 0 kg sehingga kapasitas pengangkutan tidak boleh kurang dari $0 \mathrm{~kg}$ atau tidak ada.

2. Kendala jam tenaga kerja

Upper bound: untuk proses pengangkutan karet, membutuhkan jam tenaga kerja infinity (tidak terbatas) Lower bound: untuk jam tenaga kerja tidak boleh kurang dari 71.875 detik atau kurang lebih 20 jam kerja agar tidak mempengaruhi solusi diatas. 
ISSN 2614-5278 (media cetak), ISSN 2548-8368 (media online)

Available Online at https://ejurnal.stmik-budidarma.ac.id/index.php/mib DOI 10.30865/mib.v5i2.2928

\section{b. Saluran Kedua}

Hasil pengujian menggunakan aplikasi QM untuk mengoptimalkan keuntungan pada saluran kedua berdasarkan data petani 1 dan pengumpul desa/kecamatan 1 dan kendala-kendala pada saluran kedua dilihat pada gambar 3 berikut:

\begin{tabular}{||l|l|l|l|l|l|}
\hline $\begin{array}{l}\text { (ug Linear Programming Results } \\
\text { (untitled) Solution }\end{array}$ & X1 & X2 & & & Dual \\
\hline Maximize & 7923 & 6740 & & RHS & \\
\hline Kendala Kapasitas Alat A ... & 20 & 18 & $<=$ & 10000 & 396.15 \\
\hline Kendala Jam Tenaga Kerja & 60 & 50 & $<=$ & 57600 & 0 \\
\hline Solution & 500 & 0 & & 3961500 & \\
\hline
\end{tabular}

Gambar 3. Hasil Pengujian aplikasi pada saluran kedua

Dari hasil pengujian aplikasi QM didapatkan solution pada saluran kedua produk jenis A yakni solution sebesar 500. Jadi didapatkan perhitungan solution X1=500 dikalikan dengan keuntungan X1=7923. Jadi keuntungan maksimal saluran kedua pada bulan januari adalah Rp. 3.961.500.

Analisis sensitivitas pada petani 1 dan pengumpul desa/kecamatan 1 pada saluran kedua dilihat pada gambar 4:

\begin{tabular}{|l|r|r|r|r|r|}
\hline \hline Variable & Value & Reduced ... & Original Val & Lower Bou... & Upper Bou... \\
\hline X1 & 500 & 0 & 7923 & 7488.89 & Infinity \\
\hline X2 & 0 & 390.7 & 6740 & -Infinity & 7130.7 \\
\hline & Dual Value & Slack/Surp ... & Original Val & Lower Bou ... & Upper Bou ... \\
\hline Kendala Kapasitas Alat A... & 396.15 & 0 & 10000 & 0 & 19200 \\
\hline Kendala Jam Tenaga Kerja & 0 & 27600 & 57600 & 30000 & Infinity \\
\hline
\end{tabular}

Gambar 4. Analisis Sensitivitas pada saluran kedua

Berdasarkan hasil analisis sensitivitas pada gambar 4, terdapat lower bound dan upper bound yang berguna untuk analisis sensitivitas pada saluran kedua:

1. Kendala kapasitas alat angkut

Upper bound: untuk proses pengangkutan karet, kapasitas alat angkut ditambahkan sampai berkisar $19.200 \mathrm{~kg}$ tidak akan mengubah solution diatas. Jika kapasitas alat angkut ditingkatkan maka akan mempengaruhi total biaya beban dan total keuntungan yang diperoleh.

Lower bound: untuk proses pengangkutan karet, batas bawah kapasitas pengangkutan bernilai $0 \mathrm{~kg}$ sehingga kapasitas pengangkutan tidak boleh kurang dari $0 \mathrm{~kg}$ atau tidak ada.

2. Kendala jam tenaga kerja

Upper bound: untuk proses pengangkutan karet, membutuhkan jam tenaga kerja infinity (tidak terbatas)

Lower bound: untuk jam tenaga kerja tidak boleh kurang dari 30.000 detik atau kurang lebih 9 jam kerja agar tidak mempengaruhi solusi diatas.

\section{c. Saluran Ketiga}

Hasil pengujian menggunakan aplikasi QM untuk mengoptimalkan keuntungan pada saluran ketiga berdasarkan data petani 1 dan UPPB 1 dan kendala-kendala pada saluran ketiga dilihat pada gambar 5:

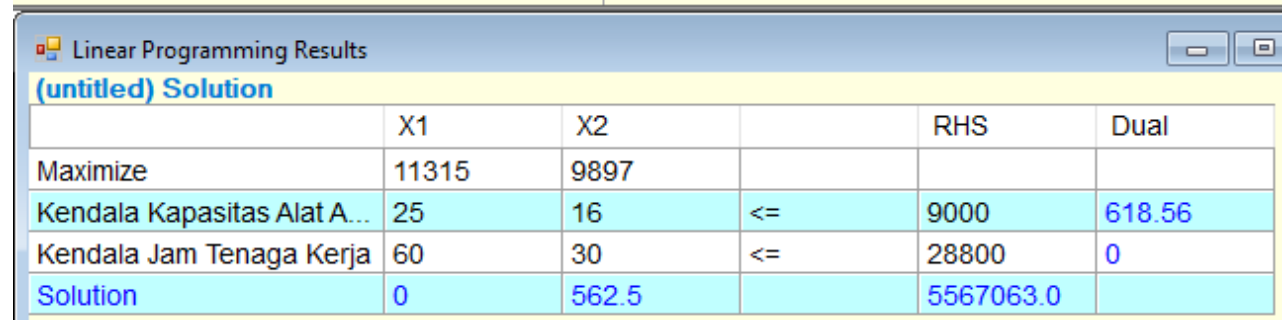

Gambar 5. Hasil Pengujian pada saluran ketiga

Dari hasil pengujian aplikasi QM didapatkan solution pada saluran ketiga produk jenis B yakni solution sebesar 562,5. Jadi didapatkan perhitungan solution X2=562,5 dikalikan dengan keuntungan X2=9897. Jadi keuntungan maksimal saluran ketiga pada bulan januari adalah Rp. 5.567.063.

Analisis sensitivitas pada petani 1 dan UPPB 1 pada saluran ketiga dapat dilihat pada gambar 6 berikut: 
JURNAL MEDIA INFORMATIKA BUDIDARMA

Volume 5, Nomor 2, April 2021, Page 600-608

ISSN 2614-5278 (media cetak), ISSN 2548-8368 (media online)

Available Online at https://ejurnal.stmik-budidarma.ac.id/index.php/mib

DOI $10.30865 /$ mib.v5i2.2928

\begin{tabular}{||l|r|r|r|r|r|}
\hline (untitled) Solution \\
\hline Variable & Value & Reduced ... & Original Val & Lower Bou... & Upper Bou... \\
\hline X1 & 0 & 4149.06 & 11315 & -Infinity & 15464.06 \\
\hline X2 & 562.5 & 0 & 9897 & 7241.6 & Infinity \\
\hline Kendala Kapasitas Alat A... & Dual Value & Slack/Surp... & Original Val & Lower Bou... & Upper Bou... \\
\hline Kendala Jam Tenaga Kerja & 618.56 & 0 & 9000 & 0 & 15360 \\
\hline
\end{tabular}

Gambar 6. Analisis Sensitivas pada saluran ketiga

Berdasarkan hasil analisis sensitivitas pada gambar 6, terdapat lower bound dan upper bound yang berguna untuk analisis sensitivitas pada saluran ketiga:

1. Kendala kapasitas alat angkut

Upper bound: untuk proses pengangkutan karet, kapasitas alat angkut ditambahkan sampai berkisar $15.360 \mathrm{~kg}$ tidak akan mengubah solution diatas. Jika kapasitas alat angkut ditingkatkan maka akan mempengaruhi total biaya beban dan total keuntungan yang diperoleh

Lower bound: untuk proses pengangkutan karet, batas bawah kapasitas pengangkutan bernilai $0 \mathrm{~kg}$ sehingga kapasitas pengangkutan tidak boleh kurang dari $0 \mathrm{~kg}$ atau tidak ada.

2. Kendala jam tenaga kerja

Upper bound: untuk proses pengangkutan karet, membutuhkan jam tenaga kerja infinity (tidak terbatas)

Lower bound: untuk jam tenaga kerja tidak boleh kurang dari 16.875 detik atau kurang lebih 5 jam kerja agar tidak mempengaruhi solusi diatas.

\subsection{Implementasi Program}

Website sistem informasi merupakan website untuk mengelola transaksi penjualan karet berupa data harga setiap saluran. Aktor website sistem informasi harga terdiri dari saluran pertama (petani A pengumpul desa, dan pengumpul kecamatan), saluran kedua (petani B dan pengumpul desa/kecamatan) dan saluran ketiga (petani $\mathrm{C}$ dan UPPB). Berikut tampilan website sistem informasi harga:

a. Halaman Login

Halaman login merupakan halaman untuk mengakses halaman utama berdasarkan level pengguna.

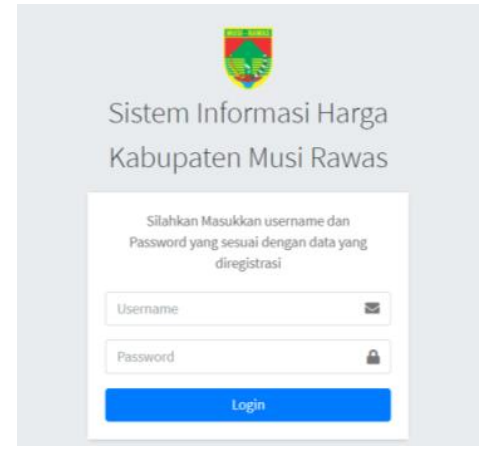

Gambar 7. Halaman Login

b. Halaman Utama Petani

Halaman utama petani merupakan halaman yang pertama kali muncul pada saat berhasil login level petani dan dapat melihat transaksi penjualan karet setiap petani berdasarkan akun login yang terdaftar.

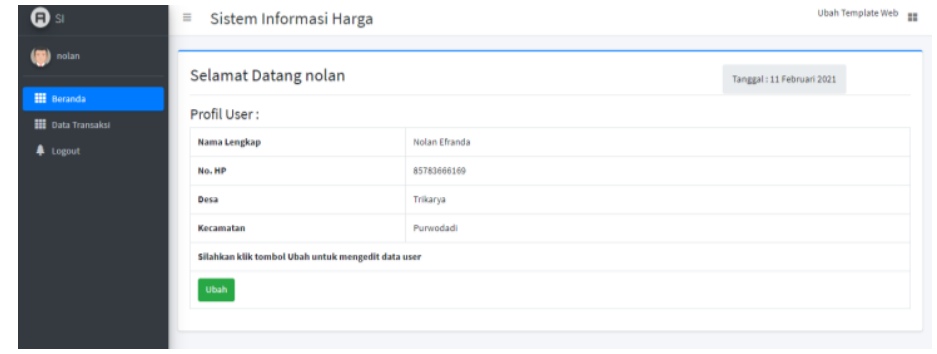

Gambar 8. Halaman Utama Petani

c. Halaman Utama Pengumpul

Halaman utama pengumpul merupakan halaman untuk mengakses semua aktivitas pengumpul seperti mengelola data harga, user, transaksi, beban dan melihat laporan penjualan berdasarkan akun login. 

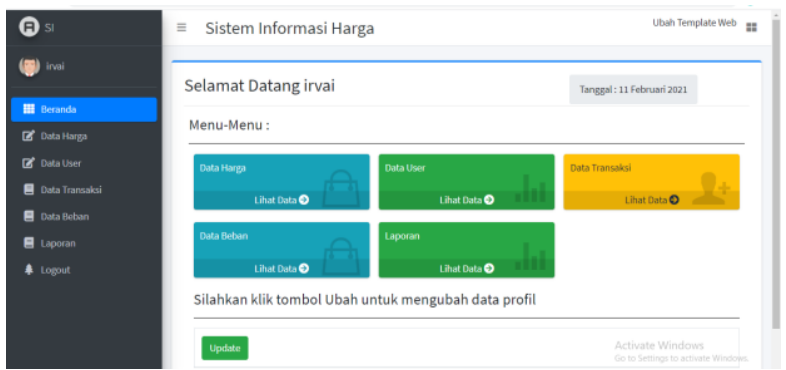

Gambar 9. Halaman Utama Pengumpul

\section{KESIMPULAN}

Dalam penelitian ini, membahas mengenai optimasi rantai pasok karet yang ada di kabupaten Musi Rawas. Optimasi rantai pasok karet digunakan untuk mendapatkan keuntungan maksimal dari rantai pasok karet tersebut. Data hasil penjualan karet setiap saluran rantai pasok dikelola menggunakan sistem informasi berbasis website. Data tersebut kemudian dikembangkan menggunakan model pemrograman linier programming diolah dengan aplikasi QM untuk mendapatkan optimasi keuntungan maksimal setiap saluran rantai pasok karet. Metode analisis yang digunakan dalam penelitian ini adalah metode Linier Programming (LP). Kapasitas alat angkut dan jam tenaga kerja dijadikan sebagai fungsi kendala sedangkan fungsi tujuannya adalah memaksimalkan keuntungan distribusi dari setiap saluran rantai pasok karet. Dari hasil pengujian aplikasi Quantitative Management (QM) dengan sampel petani 1, pengumpul desa 1 dan pengumpul kecamatan 1 pada saluran pertama bulan januari didapatkan solution produk jenis A yakni sebesar 625 dan keuntungan X1=8218, kemudian dikalikan jadi keuntungannya sebesar Rp. 5.136.250. Dari hasil pengujian aplikasi Quantitative Management (QM) dengan sampel petani dan pengumpul desa/kecamatan 1 pada saluran kedua bulan janurari didapatan solution produk jenis A yakni sebesar 500 dan keuntungan X1=7923, keuntungannya sebesar Rp. 3.961.500. Dari hasil pengujian aplikasi Quantitative Management (QM) dengan sampel petani dan UPPB 1 pada saluran ketiga bulan janurari didapatan solution produk jenis B yakni sebesar 562.5 dan keuntungan X2=9897, keuntungannya sebesar Rp. 5.567.063. Jadi dari hasil analisis menggunakan aplikasi QM, keuntungan maksimal dari rantai pasok karet rakyat terdapat pada saluran ketiga.

\section{UCAPAN TERIMAKASIH}

Terima kasih kepada Dinas Perkebunan kabupaten Musirawas yang telah memberikan izin penelitian serta Bapak Ibu Dosen Universitas Bina Darma yang telah membimbing penulis dalam menyelesaikan penelitian ini.

\section{REFERENCES}

[1] Mirza antoni dan Erni purbiyanti, "Saluran Pemasaran dan Bentuk Pasar Karet Rakyat dan Dampaknya bagi Kesejahteraan Petani Karet Rakyat di Sumatera Selatan," 2016.

[2] R. E. \& R. D, "Supply Chain Management Concept "Strategies for Managing Supply Chain Management for Modern Companies in Indonesia."

[3] J. H. dan B. Render, Manajemen Operasi. Jakarta: Salemba Empat, 2015.

[4] F. I. Dkk, "Model Optimasi Perancangan Jaringan Rantai Pasok Biomassa dari Tandan Kosong Kelapa Sawit di Sumatera Barat," J. Optimasi Sist. Ind., vol. 18, no. 1, pp. 1-13, 2019.

[5] R. D. Herdiansyah, "Peningkatan Kinerja Pemasaran Karet Alam Rakyat melalui Optimalisasi Rantai Pasok," J. TIDP, vol. 2, no. 3, pp. 151-158, 2016.

[6] P. S. DEWI ROSA INDAH, "PENERAPAN MODEL LINEAR PROGRAMMING UNTUK MENGOPTIMALKAN JUMLAH PRODUKSI DALAM MEMPEROLEH KEUNTUNGAN MAKSIMAL (Studi Kasus pada Usaha Angga Perabot)," J. Manaj. Inov., vol. 10, no. 2, 2019.

[7] A. M. H. Bedy Sudjarmoko, "Manajemen Rantai Pasok Benih Unggul Karet," SIRINOV, vol. 3, no. 1, 2016.

[8] M. I. dkk Herdiansyah, "Pemodelan Jaringan Green Supply Chain Kawasan Industri Kerajinan Jumputan," in Seminar Nasional Teknologi Informasi Dan Komunikasi, 2018.

[9] A. A. M. A. Darius Antoni, "E-Supply Chain Management Value Concept for the Palm Oil Industry," J. Sist. Inf. (Journal Inf. Syst., vol. 15, no. 2, 2019.

[10] N. E. Silaen, "Perencanaan, Model Optimasi dalam Suplai, Logistik dan Rantai,” Universitas Sumatera Utara, 2018.

[11] B. Eman Lesmana, Badrulfalah, "Aplikasi Model Mixed Integer Linier Programming untuk Pengolahan dan Pendistribusian pada Industri Perikanan (Studi Kasus: PT. Multi Mina Rejeki),” J. Teorema Teor. dan Ris. Mat., vol. 3, no. 2, pp. 195-206, 2018

[12] Ngusman, "Perencanaan Jumlah Produksi Optimum dengan Metode Linier Programming pada UD Muktijaya COR di Ciamis," J. Media Teknol., vol. 5, no. 1, 2018.

[13] B. sudjarmoko dan A. Muis, "Manajemen Rantai Pasok Benih Unggul Karet," J. SIRINOV, vol. 3, pp. 31-38, 2016.

[14] S. H. dan A. A. Setyawan, "Manajemen Rantai Pasok Kayu Gaharu di Kalimantan Barat," J. Ekon. Manaj. Sumber Daya, 
JURNAL MEDIA INFORMATIKA BUDIDARMA

Volume 5, Nomor 2, April 2021, Page 600-608

ISSN 2614-5278 (media cetak), ISSN 2548-8368 (media online)

Available Online at https://ejurnal.stmik-budidarma.ac.id/index.php/mib

DOI 10.30865/mib.v5i2.2928

vol. 18, no. 2, pp. 92-101, 2016.

[15] P. Y. S. Ni Putu Krisnadewi, "Optimalisasi Produksi pada Usaha Kecil Kripik Terry di Desa Nyanglan Kaja, Kecamatan Tembuku Kabupaten Bangli,” E-Jurnal Manaj. Unud, vol. 7, no. 11, pp. 6011-6040, 2018.

[16] L. H. Dkk, "Penerapan Linier Programming dalam Penentuan Kombinasi Produk Guna Memaksimalkan Laba pada UD Putera Sroedji Jember," J. Bisnis dan Manaj., vol. 12, no. 3, pp. 300-312, 2018.

[17] A. . dan M. S. Rosa, Rekayasa Perangkat Lunak. Bandung: Informatika, 2018.

[18] F. A. J. dan T. F, "Rancang Bangun Sistem Informasi Tender Karet Desa Jungai menggunakan Metode Waterfall," J. SISFOKOM, vol. 06, no. 2, 2017. 